\title{
Multidimensional Classifications: Past and Future Conceptualizations and Visualizations ${ }^{\dagger}$
}

\author{
Charles van den Heuvel \\ Huygens Institute for the History of the Netherlands, Royal Netherlands Academy \\ of Arts and Sciences, Postbus 90754 NL-2509 LT Den Haag, The Netherlands, \\ <charles.van.den.heuvel@huygens.knaw.nl>
}

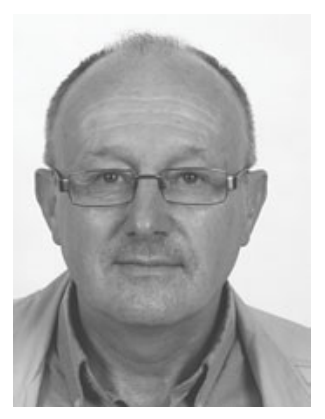

Charles van den Heuvel is Head, Research Group History of Science and Scholarship at the Huygens Institute for the History of the Netherlands of the Royal Netherlands Academy of Arts and Sciences. He publishes regularly on history of architecture and town planning, history of cartography, history of science, and history of library and information science. Themes of interest in the latter discipline are the history of classification, history of the WWW, and the history of visualizations of knowledge. Currently, he is writing a book entitled "Imagining Interfaces to Universal Knowledge. The visualizations of Paul Otlet."

Van den Heuvel, Charles. Multidimensional Classifications: Past and Future Conceptualizations and Visualizations. Knowledge Organization. 39(6), 446-460. 46 references.

ABSTRACT: This paper maps the concepts "space" and "dimensionality" in classifications, in particular in visualizations hereof, from a historical perspective. After a historical excursion in the domain of classification theory of what in mathematics is known as dimensionality reduction in representations of a single universe of knowledge, its potentiality will be explored for information retrieval and navigation in the multiverse of the World Wide Web.

Received 22 July 2012; Revised 31 August 2012; Accepted 31 August 2012

$\dagger$ This paper is an adaptation and augmented version of a paper presented at the NASKO 2011 conference: Charles van den Heu-
vel. 2011. Multidimensional classifications: Past and future conceptualizations and visualizations. In Smiraglia, Richard P., ed.
Proceedings from North American Symposium on Knowledge Organization, Vol. 3. Toronto, Canada, pp. 105-21. The author
wishes to thank Thomas M. Dousa, University of Illinois, at Urbana-Champaign for his generosity in bringing the importance
of the ideas of Gérard Cordonnier on multidimensionality in intellectual space to his attention. Thomas hopes to discuss in the
near future the ignored role of Cordonnier in the historiography of KO from a linguistic and epistemological point of view. Fi-
nally, the author is indebted to the anonymous reviewer who pointed him to the theory of transdisciplinarity and levels of real-
ity of the Romanian astro-physicist Basarab Nicolescu. His ideas deserve more attention than I could discuss in the context of
this article and need more exploration.

\subsection{Introduction}

Licklider observed in his Libraries of the Future that most studies of topological and metric space analogies (for the greater part written in the domain of information retrieval) focused so far on linear methods. Moreover, he claimed that "those studies have not emphasized the space concept, and they have led to little or no consensus even about the dimensionality, much less about the identities of the dimensions, of any such thing as 'information space' or 'semantic space' or the 'space of knowledge”' (Licklider 1965, 77). We agree that such a consensus still does not exist, but state at the same time that, in the history of classification, the concepts space and dimensionality were explored. Although conceptualizations of space 
and dimensionality in the organization of knowledge are much older, we start our historical exploration in $19^{\text {th }}$ century with three interrelated debates: on the classification of the sciences, on evolution, and on atomist theory. Conceptualizations of dimensionality can be traced in the history of classification of the sciences. For instance, Herbert Spencer (1864), in his criticism on the linear and historical sequential representation of the evolution of the sciences by the positivist thinker Auguste Comte, argued that sciences are so complex that the relationships only can be explained in a multidimensional way. The discussion on the evolution of the sciences stood in a wider context of the $19^{\text {th }}$ century debate on (biological and organic) evolution. After Darwin's publication of On the Origin of Species in 1859, the idea that life had evolved in a process of natural selection became particularly an active source of academic debates focusing on the philosophical, social, and religious dimensions of the evolution of human life. Studies in the emerging discipline of psychology (Baine, Wundt, Fouillée, Bergson) tried to include the evolution of mental order and explored the internal dimension or "psyche" of man. Related to these discussions on the classification of the sciences and of evolution, there was a third debate that focused on the origin and substance of the universe (atomism). Since the atomic theory that John Dalton formulated in his A Nerw System of Chemical Philosophy, which appeared in the years 1808 and 1810, the debate on atoms and voids in the universe got a new impetus. At first sight, this debate seems remote from classification in library science. However, the $19^{\text {th }}$ century developments in astronomy had both an impact on the library sciences via the old metaphor of the universe of knowledge and via new notions of time and space in atomic theory.

In other studies, we discussed considerations on space and multidimensionality of classificationists such as Richardson, Otlet, Bliss, Ranganathan, and their historiographers Miksa and Beghtol, who used the universe of knowledge metaphor in their debates on hierarchy and flexibility in their strive to promote their classification system and to develop a new classification theory (Van den Heuvel and Smiraglia 2010; Smiraglia and Van den Heuvel 2011). In another study, we focused in particular on multidimensionality in visualizations of universes of knowledge (Van den Heuvel and Akdag 2011).

We also briefly explored the potential impact of atomic theory on the UDC and observed that the pioneer of documentation Paul Otlet followed the debates on astrophysics of the beginning of the 20th century closely. Although we concluded that new views on "spacetime" did not lead to change of the UDC, it was argued that Otlet was nevertheless aware of the contradiction with his separation of space and time in his classification system, which he hoped would be solved with further advancements in mathematics (Van den Heuvel and Smiraglia 2010). Moreover, other phrases in his publication Monde of 1935 suggest that Otlet was interested in the spatial consequences of the developments in atomic theory. He observed that, since the theories of Riemann and Einstein, another "hypergeometrie" should be considered, and he suggested a new discipline of "spatiologie" (Otlet 1935, 304-306). Otlet did not explain further what he intended with these new disciplines of hypergeometry and spatiology, but unpublished manuscripts in the archives of the Mundaneum reveal that he was studying the implications of spacetime and notions of events in the work of Samuel Alexander, Bertrand Russell, and Alfred North Whitehead for synthesis of knowledge. Although these new notions of space (and time) did not have an impact on the UDC, unpublished drawings in the abovementioned archives reveal that multidimensionality and space played a crucial role in Otlet's first conceptualizations of classification. We will compare some drawings in this manuscript of Otlet to the mappings of Ranganathan of a multi-dimensional universe of knowledge along a one-dimensional space (line) (Ranganathan 1967). Finally, the notions of dimensionality in "intellectual space" of the ignored theorist of classification Gérard Cordonnier will be discussed.

After this historical excursion in the domain of classification theory of what in mathematics is known as dimensionality reduction in representations of a single universe of knowledge, we try to explore its potentiality for information retrieval and navigation multiple universes or multiverse of knowledge. We argue that Otlet's and Ranganathan's mappings of multi-dimensional knowledge spaces on a onedimensional one or line in combination with the development of a viewer based on parallel vision of documents developed for Nelson's XanaduSpace can be useful to retrieve knowledge classes in formal ontologies and folksonomies and their contexts from different perspectives. On the basis of predictive models of the future structure of the World Wide Web by Albert-László Barabási, we argue that the dream of dataintegration of all knowledge seems to be even more remote than in the past, but that the development of the abovementioned viewer could be useful for information retrieval within a constellation of multiple 
(sub-) universes that develop in a modular and at the same time self organizing way.

\subsection{Historical notions of multidimensionality and of space in classifications}

Probably the first author who discussed the importance of these more general debates on classification of the sciences, on the evolution of mankind and the human mind, and, finally, of the universe of knowledge for the emerging discipline of Library Science was Henry Evelyn Bliss (1929). Most of the names mentioned in his historiographical study of classifications have relevance for conceptualizations of space and dimensionality: the in-between spaces of Cutter's "transient classes," Richardson's historical dependency of spaces for new classes, and Sayer's observations on parallel-orders. The role of these conceptualizations was touched upon as part of the attempt for formulate a faceted classification theory, in particular in discussions on the Colon Classification by the Classification Research Group (1951) and by several authors such as S.R Ranganathan (1951, 1957, 1967), Thomas Daniel Wilson (1972), Clare Beghtol (2008), Francis Miksa (1992, 1998), and Kathryn La Barre (2006). In other studies, we tried to put (the self-proclaimed) role of Ranganathan in the development of the "first classification theory" in a historical context by comparing the CC to the UDC (Smiraglia and Van den Heuvel 2011, 44; Van den Heuvel and Akdag, 2011) and to discuss it in more detail (Van den Heuvel 2013 forthcoming). In this paper, we continue our exploration of faceted classification systems. This is based on the assumption that the concept space and multi-dimensionality play a more prominent role herein and that they are more suitable for a comparative analysis. Secondly, both Paul Otlet and Ranganathan used visualizations of multidimensional aspects of their classifications which can be compared (Van den Heuvel 2008; Ranganathan 1967; Miksa 1992). Finally, both Otlet and Ranganathan discussed the role of language and notation in relation to spatial sequence and multi-dimensionality in their faceted classifications. The latter issue is of importance for a comparison with discussions about logical relations between concepts and a classification (Farradane 1952; Smiraglia et al. 2011) and between knowledge organization and hypertext (Nelson 2004; Nelson and Adamson Smith 2007; Rayward 1994).

\subsection{Multi-dimensional thought and one-dimensional arrangement}

The observation of Licklider that most studies of topological and metric space analogies focused so far on linear methods is partly true. As we will see, the mathematical method of dimension reduction was indeed applied in practical ways. Not seldom was it that what Licklider had called the identities of these dimensions were ignored or reduced in these very same practical applications of linear methods. "The business of the librarian and the function of library tools are to help every unit of thought-energy to reach its destiny," Ranganathan $(1951,95)$ stated in a paragraph on the purpose of classification. The purpose of classification is, in his view, a process of transformation from a multidimensional space of thought to a one-dimensional space that is easier to handle and in which it is easier to perceive things. Ranganathan $(1951,96)$ writes:

Thought is multi-dimensional. But we are onedimensional beings - that is we still prefer all things to be handled to be arranged in onedimension .... This means that classification is essentially a transformation of a manydimensional universe into a uni-dimensional, unidirectional one. The machine tools are expected to perform this transformation.

In his Prolegomena to Library Classification Ranganathan gives an example of a mapping of subjects belonging to a multi-dimensional universe into a system of points along a line (Ranganathan 1957; 1967). He visualized the mathematical mapping of space of large number of dimensions on one of a smaller number in a so-called Apupa arrangement in the third edition of his work (Ranganathan 1967, figs. 19, 20, 21) (See, Figure 1b).

In an earlier publication, Frits Donker Duyvis, the secretary of the International Institute of Bibliography and committee member of the revision of the UDC had made clear that Ranganathan's Colon Classification was much indebted to Otlet's multidimensional classification (Donker Duyvis 1951). Although Donker Duyvis, in his presentation of the UDC as a practical method, argued that Otlet and La Fontaine never had the intention to develop it as a theory, Otlet used this term explicitly to describe his visual explorations of the multidimensional character of his classification. In his manuscript Theorie schematique de la Classification of 14 December 1908, Otlet describes and visualizes in so-called "schemes 

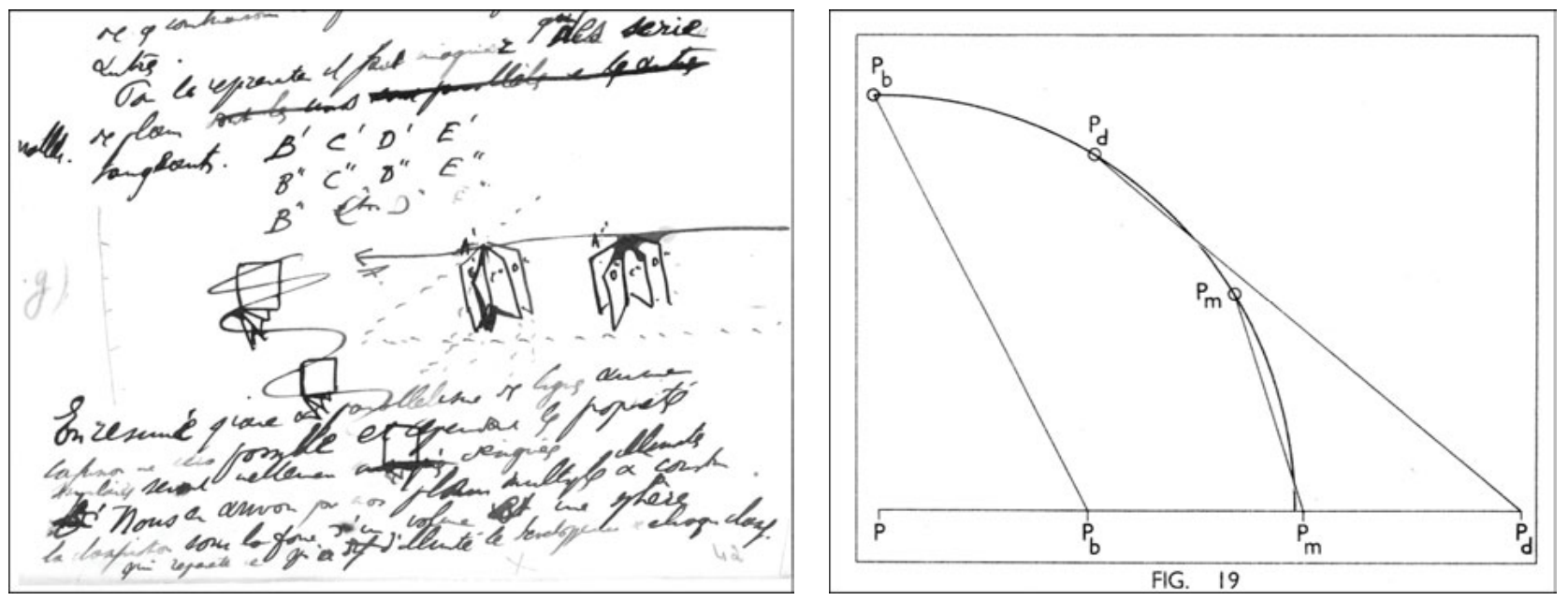

Figure $1 a+b$. Dimension reduction in the work of Otlet and Ranganathan

Otlet, Theorie schematique de la Classification of 14 December 1908

(C) Mons, Mundaneum EUM Farde 9 N. 39)

Ranganathan (1967) Fig. 19

fondamentaux" (fundamental schemes) the multidimensional reduction of the content of various formats to one line and the recombination of these elements in multi-dimensional knowledge constructions (see, Figure 1a). Various sources of information coming from multiple direction are brought in one line and comparable content is expressed in linear notations of letters $\mathrm{a}, \mathrm{a} 1, \mathrm{~b}, \mathrm{~b} 1, \mathrm{~b} 2$, etc.). In successive pages, he translates these dimensions in numerical notation of the UDC and includes sketches of multidimensional knowledge objects in which these various classes meet.

The many crossing outs of words and images in the Theorie schematique de la Classification and great amount of sketches of related representation of multidimensional classifications reveal that Otlet's theory was not fully developed yet and that he was still trying to work out the relationships between the various elements of his theory. In the same years that Otlet was working on his schematic theory of classification, he was also developing ideas on substitutes for the book (Van den Heuvel 2008; Van den Heuvel 2009; Van den Heuvel and Rayward 2011). He proposed that texts, but also other forms of documents such as formulas, charts, images, and schemes should be dissected into their basic elements and recorded on standardized cards or sheets of paper. These chunks of information could then be reassembled over and over again in new combinations of publication formats. Furthermore, Otlet suggested that this process-which he described as the Monographic Principle—can operate mechanically. "Documentation,"
Otlet $(1907,11)$ observed, "is not limited to recording information but will allow its automatic retrieval at any moment it is required; [documentation is] a vast intellectual mechanism designed to capture and condense fragmentary and scattered information and to disseminate it wherever it is needed." Otlet realized that the reconceptualization of the book also had implications for his classification. In effect, the replacement of the book by a database of cards required new ways of linking related information chunks that were dispersed over various cards. The possible links were complex and could, in Otlet's view, only be organized in multidimensional orders. A poster of April 1916 (Figure 2) with the title Elements de schematique in which the various components are represented in an order of 12 successive images reveals Otlet's attempts to integrate the processes of dissecting books into cards and of multidimensional classification in one semi-mechanical device, a rotating polygonal card system, that he called the Book (Van den Heuvel 2013b, forthcoming).

\subsection{Conceptualizations of metric and of topological space}

Although Licklider was right in his observation that most studies of topological and metric space analogies focused on the practical application of dimension reduction in information retrieval, we do not support his argument that there were hardly conceptualizations of space and multidimensionality and their identities. We argue that, as part of several attempts to 


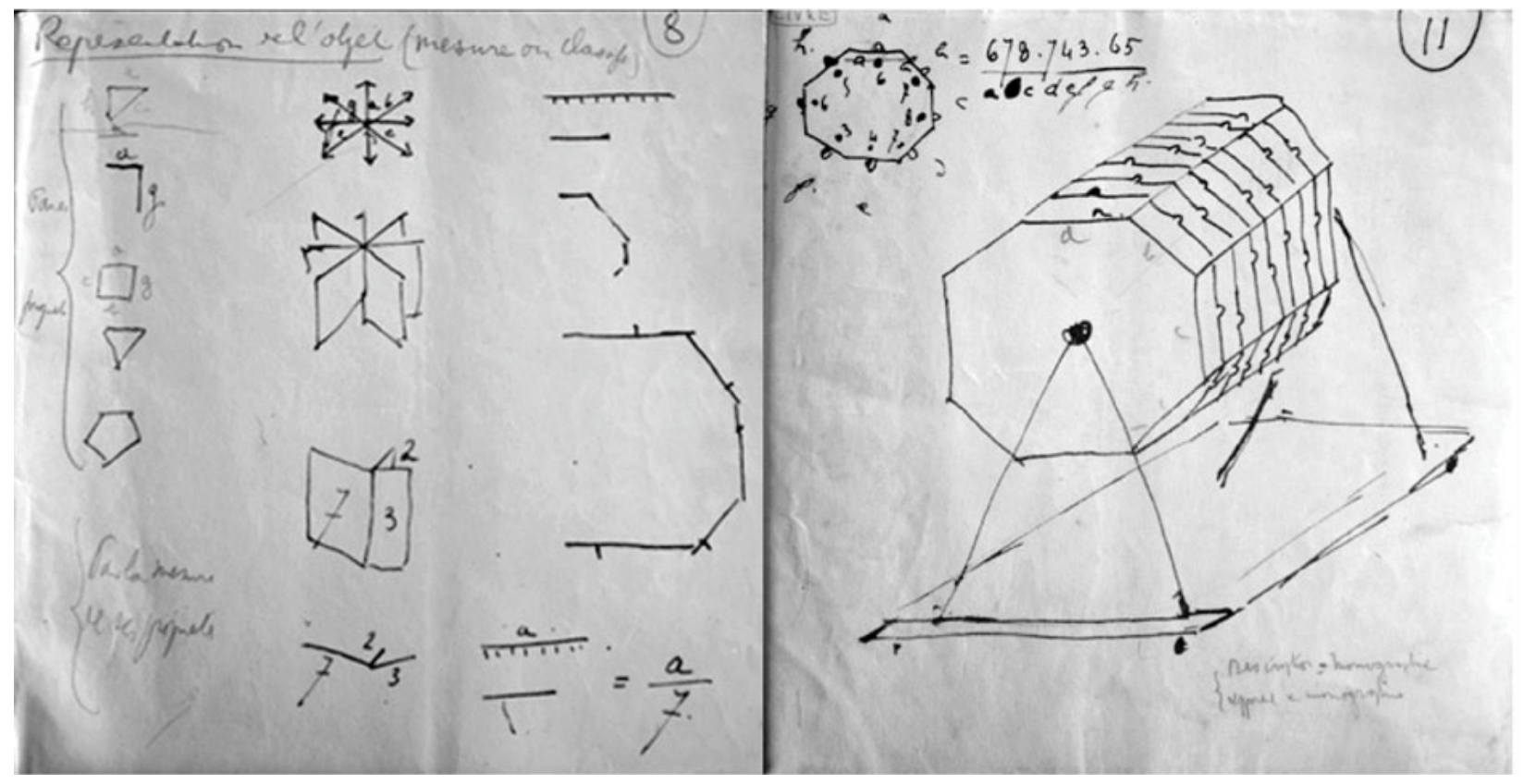

Figure 2. P. Otlet: Design Elements of Schematics

Composition of details 8 (Representaion of object: measured or classified) and 11 (Book) PPPO-281 - Schematique - Ideographique- Elements de Schematique (1916)

Mons, Mundaneum (C)

formulate a classification theory, conceptualizations of space and dimensionality were brought forward. Paradoxically, space and dimensions were especially discussed as part of the problem to handle time, evolution, and synthesis in the development of the universe of knowledge.

When Paul Otlet and the most famous Modernist architect of the 20th century Le Corbusier made plans together for a World City on the banks of Lake Geneva in Switzerland, they designed its main building, the Mundaneum in the form of a spiral to symbolize the increase and development of global knowledge. Ranganathan used a similar spiral form in a diagram that expressed the development of the universe of knowledge as a dynamic continuum (Ranganathan 1957, 250-51). The spiral is, for Otlet and Ranganathan, an expression of expansion of total knowledge on the long term, which encompasses (non visible) short successive cyclic movements (Otlet 1935, 318; Ranganathan 1957, 249). Otlet, as we will see, called these short term cyclic movements "evenements," and Ranganathan decribed them as a "continuous cascade of new micro-thoughts" in the universe of knowledge. Both Otlet and Ranganathan were aware of the tensions between the factors time and evolution, on the one hand, and the synthesis of elements of facets of knowledge within their classification systems. In an unpublished manuscript in the Archives of the Mundaneum in Mons (Belgium) with the title "Relations fondamentales" of 9 April 1928, Otlet refers explicitly to the works of Samuel Alexander (known for this concept of bottom-up emerging synthesis) and the philosophers/mathematicians Bertrand Russell and Alfred North Whitehead, who both questioned the idea of an universal synthesis and who used notions of events as occurrences. In this manuscript, that, according to its subheading, discusses "the philosophy and research of a new scheme (schema) of time and space," Otlet stated that Alexander and Russell, replaced the classical view of permanent synthesis by "a collection of relative events." Whitehead, in Otlet's view, broke with the notion of synthesis altogether. Whitehead rejected, indeed, the idea that each object has a simple spatial or temporal location. If he had been familiar with the work of Otlet, he would probably had reckoned it to what he called in his Science of the Modern World of 1926: "The Fallacy of Misplaced Concreteness," or the error of mistaking the abstract for the concrete. According to Whitehead $(1945,114)$, it would be wrong to see in a spatial point more than abstraction, and every real-life object may be understood as a constructed series of events:

In a certain sense everything is everywhere at all times. For every location involves as aspects of 
itself in every other location. Thus every spatiotemporal standpoint mirrors the world.

Whitehead's view that all things are in a continuous flux is quite different from the spatio-temporal notions of Otlet and Ranganathan. Otlet $(1935,331)$ made a distinction in Monde between a) the development of reality and b) the development of "ideas in systems and syntheses with an assimilation and remodelling of what is new," which c) at certain moments in time intersect at certain points. Ranganathan does follow this line of reasoning of successive syntheses in his loops of "micro-thought." However, whereas Otlet thought that this development could be handled by an update of the UDC from time to time, Ranganathan was convinced that it implied a fundamental change in classification. The latter observed that there is "wastage incidental to 'research in parallel" in the development universe of knowledge that has to be eliminated "by organizing 'research in series”" (Ranganathan 1957, 248). To this end, Ranganathan introduced "depth classification," which he defined as: "a scheme of classification fitted to reach coextensiveness and expressiveness in the classification of micro-thought having many rounds and levels of facets, and isolates of high orders in any all of them" (Ranganathan 1957, 241).

This depth classification of microthought was, for Ranganathan, a strategy to prevent the reversion of research in series in research in parallel (Ranganathan 1957). However, every classification, in Ranganathan's view, has its limitations. Its scheme depends on what is regarded as the minimum, essential invariant. The establishment of this invariant is a forced compromise or, in Ranganathan's words, "a scheme is obliged to do so only for the most widely used approach;" this does not only have implications for classification, but for synthesis, as well (Ranganathan 1957, 255):

Much of the difficulty, due to classification being equivalent to the mapping of a multidimensional space over a one-dimensional one, arises in the synthesis of the facets. If there are $n$ facets in micro-thought, a scheme has to chose forcedly one of the $n$ ! ways of arranging them in a class number.

The mathematics of this mapping, Ranganathan states, have not yet been worked out in detail by anybody and, for the time being, he proposes a symbiosis with cataloging to overcome the limitations of classification (Ranganathan 1957). The Library Research
Circle that was formed in 1951 in India, discussed Ranganathan's veranda mathematical aspects of classifications every Sunday. Its members modeled their approaches after Russell's and Whitehead's works on mathematics (La Barre 2006). We do not know for sure whether they discussed the views of the latter on mapping of multidimensional spaces and classification as well. Whitehead likens, in his Adventures of Ideas (1933), "non-metrical projective geometry" to what he called "the science of cross-classification" (Whitehead 1967, 137-38). Different from elementary geometry of Euclidian space, non metric projective geometry has a projective space. In this space, geometric transformations are permitted to move "points at infinity" to traditional points and vice versa that are not permitted in Euclidian space (Wikipedia 2011). Ranganathan's description of how the successive isolates in a chain within a facet, considered from the angle of the idea plane, form a "Nest of Cells in many dimensions" and, from the notational plane, a "Nest of Intervals on a line" might have been inspired by Whitehead's views on projective geometry (Ranganathan 1957, 254-255). Although Ranganathan recognized the existence of a "two-fold infinity" -an infinity in the approaches of readers of documents and an infinity in the dimensions of the universe of ideas to be organized (La Barre 2006, 43), he seems to exploit the method of projective geometry in a one directional way, i.e., the transformation from more dimensions to one, or what Licklider had called the use of linear methods in information retrieval.

A forgotten classificationist, the French naval engineer and mathematician Gérard Cordonnier, who was familiar with the principles of projective geometry as well, did not focus on the line, but on what he called "intellectual space" (Cordonnier 1944, 26-28). This intellectual space is constituted by a collection of logical relationships between ideas in the same way that physical space consists of a collection between material relationships (Cordonnier 1944). He explains how a collection of relations represented as a geometrical figure can be represented, from one point of view, as a synthesis of all projected figures possible. In a Euclidian space, the material point-Cordonnier $(1944,28)$ uses the a molecule as example-can be defined by three coordinates.

However, if you want to go beyond that point you have to deal with the parameters that defines the relative positions of atoms and another step further more dimensions are introduced that regulate them that allow the mathematician 
to start his exploration. One can say that the three visual dimensions of the world ramify in each stage of a new approximation of this internal universe and becomes inseparable of time.

Cordonnier distinguishes various types of ramifications that regulate the development of tree-like ("arboresente") structures of classifications. He is familiar with the UDC and stresses the potential of the alternative system of Bliss to connect his general classification with the needs of special classifications. Cordonnier, familiar with the Colon Classification edition of 1933, follows Ranganathan in his critique of the hierarchical tree-like structure of the UDC, a critique that was challenged by Donker Duyvis and more recently by Van den Heuvel and Akdag on the basis of a visual analysis of this classification system (Ranganathan 1951; Donker Duyvis 1951; Van den Heuvel and Akdag 2011; Van den Heuvel forthcoming). Cordonnier praises what Ranganathan had called the banyan tree structure of the Colon Classification which branches ramify and grow at the top and at the bottom. However, he also observes illogical orders in certain classes and notation in the Colon Classification and tries to take it further by a profound analysis and typology of developments and dimensions of the tree like structures of various classification in order to develop a new one. Cordonnier $(1944,7)$ states that the classificationist should not strive for giving each object or idea an unique place:

A universal classification should be a collection ordered by points of view. An object will be found in more rubrics [classes under more subject headings] of which the whole defines its place in the intellectual domain, similar to a point in space is defined by its "coordinates" or projections according to more points of view.

The notation of such a class is not presented in the form of a linear string of elementary symbols, but as a branching (rameau) with branches on various levels of subdivision. He is thinking of a ramification with two branches that do not grow necessarily in the same way, since they are sometimes enriched to express an idea more precisely or abbreviated if an idea is less interesting for a specialized node (Cordonnier 1944). Such ramification is "open" if the tree-like structure develops in all directions with full independency of its branches and "cyclic" when each of its sub branches refers to the original branch from which they all stem (Cordonnier 1944, 30-32). This is quite different from Ranaganthan's projections, since, in the case of Cordonnier, the dimension time is included in the various tree-like structures that are not only projected in, but also evolve and shape his "intellectual space."

\subsection{Limitations in visualizations of multi- dimensionality and the end of classification?!}

Although visualizations are good ways to represent spatial relationships, they are far more limited in expressions of time, of evolution, or of the character of relationships between knowledge objects. Shera (1951) states that the poly-dimensional character of the contents of books is incompatible with the traditional hierarchical schematization of knowledge, which is a linear progression from general to specific. This incompatibility also has implications for the visualizations of the classificationists who tried to balance between the hierarchical order of their systems and the multidimensionality of intellectual space. Cordonnier represents the three coordinates of $s$ (standing for symbol) on the levels, lines, and orders (subdivision of the line on each level) in a simple matrix-like figure. To express evolution or the growth of branches, he just used capital and lower case symbols $\mathrm{S}$, standing for primary and secondary branches. Ranganathan explains how he, in his illustrations of the Apupa arrangement, had to limit the amount of disciplines in his mappings of the case: the rhetorical ability of professors in various domains for one and of two characteristics expressing 1) the rhetorical ability and 2) main subjects to avoid overcrowding in the diagram (Ranganathan 1967, figs. 19, $20,21)$. Otlet was also aware of the limitations of paper, but tried to overcome these in some cases by making three-dimensional knowledge objects. He created, for instance, a three-dimensional, rotatable knowledge object to express the dynamics of language in a comparative way and in which the various classes describing grammatical features of languages could be lined up (Figure 3).

Apart from the limitations of visualizations to express time or dynamics, they are also not the most obvious means to explain the character or meanings of certain relationships. Shera observed in 1951 that we were standing at a threshold of a reorientation of the idea of classification as a result of the acknowledgement that any attempt to organize knowledge is conditioned by the social epistemology of the age it was produced (Shera 1951). Based on Whitehead's notion of referential classification, Shera $(1951,84)$ argues that any single unit of knowledge may be 


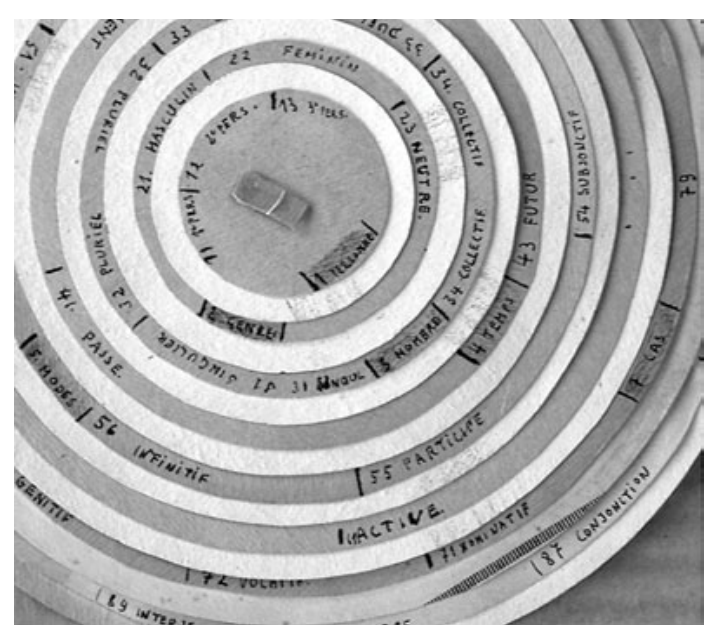

Figure 3. Otlet "Machine à parler" Three dimensional representation of language on cardboard (detail)

(C) Mons, Mundaneum EUM Model 139 26 November 1939)

meaningful in any number of different relationships depending upon the immediate purpose:

Relationship is not a universal, but a specific fact unique to things related, and just as these relations reveal the nature of the relata, so the relata determine the character of the relationship.

The character of relationships in classification and the continuous change hereof is difficult to represent. Farradane $(1952,75)$ formulated this in his "scientific theory of classification" as follows:

Owing to the difficulties of representing all possible relational series in any fixed form, printed form, each classification, shows only a limited selection, which imposes a rigid network which is mostly neither adaptable nor logically true throughout.

Farradane proposes a system of logical relations, which he calls operators, to be used as a basis for classification based on methods of perception rather than on philosophical views or the everyday experience of librarian (Farradane 1952). He tries to get a grip on the multidimensional complexity of relationships by representing each operator as a line that points in a different direction. The result is a complex diagram in which specific notations symbols and arrows are combined to express the multidimensional character of the combination of operators (Farradane 1952, 8586) (Figure 4).

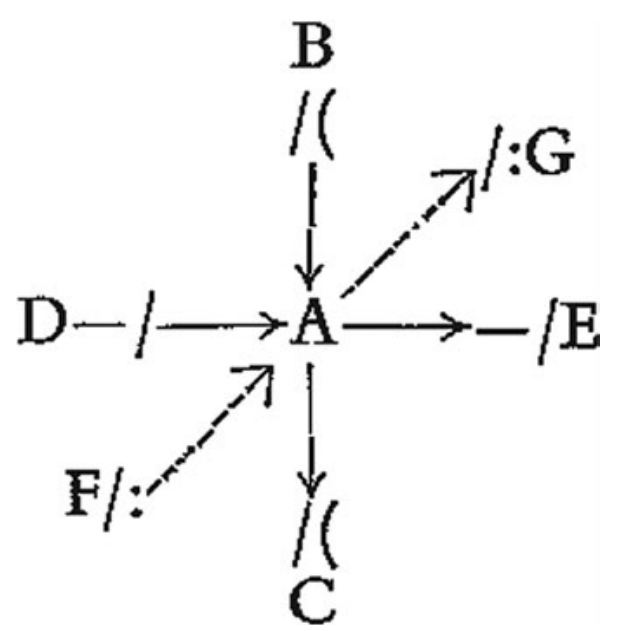

Figure 4. Farradane (1952) representation of dimensions of operators

Shera $(1957,22)$, whose choice of words strongly reflect the ideas of Whitehead, questioned the possibility of representation of logical relations in knowledge all together:

The fallacy, of course, lay in the fact that a hierarchical structure is but one pattern of thought in a universe of infinite patterns ... what is a rational or logical association for one can be quite irrational and illogical for another.

Shera believes that there is no universal system of classification to all situations, just as there is no one pattern of human thought (Shera 1957). However, Shera $(1951,81)$ does not break with classification all together; it is, in his view, just misapplied:

Classification, then, can achieve its fullest purpose as instrument of bibliographic organization only after the idea content of the book has been dissociated from its physical embodiment-its codex form.

The emphasis of separating "idea content" from its physical embodiment is not new and links Shera directly to Otlet's visions of "substitutes for the book" (Van den Heuvel 2008, 139-141). However, Shera's call to replace universal systems of classification by classification as a discipline based on concepts and concept formation, rather than to use it as a tool is fundamentally different from all other classification constructs or "theories" so far. Shera's description of the "future of classification" does not only differ in 
its emphasis on concept formation, but has farreaching implications for the role of the librarian as well, who, in his view, had to have knowledge of recent discoveries in physiology, psychology, cybernetics, information theory, linguistics, anthropology, sociology of knowledge, history of thought, and of the basic sciences of mathematics, physics, chemistry, biology, and the social sciences. He concludes, "the librarian of the future may well be regarded as the geneticist of our intellectual life" (Shera 1957, 26).

Shera stretched the role of classification and of the librarian to the limit. When he wrote his paragraph on the future of classification, bibliographic organization and traditional library methods were challenged by the rapid introduction of mechanical tools that began to take over the operations of the librarian in an automated way. It is also in this context that Licklider wrote his 1965 essay on Libraries of the Future. Similar to Shera, he dissociates the idea content of the book from the book and the library as physical bodies. However, Licklider's search of concepts and ideas behind the visible and tangible aspects of documents is no longer directed toward its implications for classification or the role of the librarian. Licklider's focus is on "transformable knowledge" and man's interaction with such knowledge in library systems for the future, which he prefers to define as "precognitive systems" to reflect their role in the advancement and application of knowledge (Licklider 1965, 6). Licklider's shift in attention towards human-computer interaction precognitive systems has consequences not only for the conceptualization of the space, which he calls the "fund of knowledge," but also of topological space and dimensionality. Licklider visualizes the changes of the fund of knowledge by comparing the information flow in existing knowledge systems and in a future simulation in which a precognitive system has been implemented (Figure 5).

In the first schematic representation, the knowledge fund (k), human beings (h), the system (s), and applications (a) are separate bodies in which human beings play a role as a "relay" in the transmission of knowledge. In the second one, which incorporates the precognitive system, we observe a transformation of these bodies. The fund of knowledge is extended into "intimate interactions" with human users that actively function as executives rather than passing on information passively. In addition to redefining the fund of knowledge, Licklider also explores the implications of human-computer interaction for topological space analogies and notions of dimensionality and the identities of dimensions. He analyses, for in-

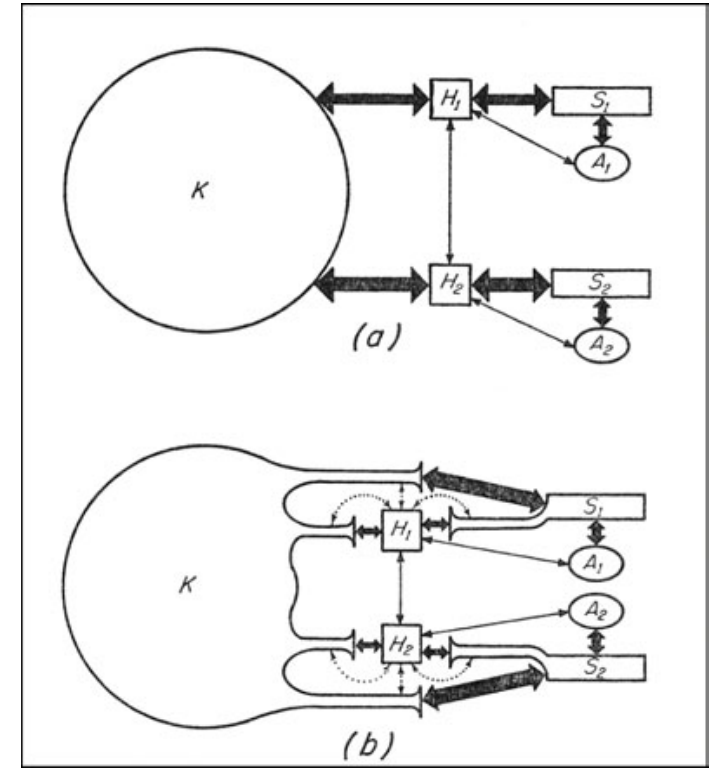

Figure 5. Licklider (1965), knowledge fund and human computer interaction before (a) and after (b) implementation of precognitive system. Cambridge, Mass.: M.I.T. Press (C)

stance, Osgood's semantic space based on many human scaling judgments of linguistic objects and asks himself how the attractiveness of the space analogy can be reconciled with logical and linguistic schemata that do not involve geometry or continuous variables. Licklider $(1965,78)$ believes that this question will not be answered soon, which is why we need:

to accept the notion, for many years at least, we shall not achieve a complete integration of knowledge, we shall have to content ourselves with diverse partial models of the universe. It may not be elegant to base some of the models in geometry, some in logic, and others in natural language, but that may be the most practical solution.

We shall come back to these partial models of the universe when we discuss the future of the topological space of the World Wide Web and its implications on information retrieval. However, first we will address conceptualizations and visualizations of multidimensionality in computer space in the work of the inventor of hypertext and hypermedia, Ted Nelson. Boyd Rayward (1994) in his well-known article $\mathrm{Vi}$ sions of Xanadu: Paul Otlet (1868-1944) and Hypertext pointed out that the concept of non-linear paths through documentation was also present in the work of Paul Otlet at the beginning of the $20^{\text {th }}$ century (Compare Figure 5a). Here, we will discuss another 
aspect that is Nelson's visualizations of linkage in multidimensional space.

\subsection{Hypertext, the World Wide Web and Xanadu space}

All conceptualizations of space, dimensionality, and the character of relationships in structures of knowledge that we discussed so far stayed within the boundaries of classifications, the realm of the librarian or the context of the library.

Similar to the publication of Licklider, the study of Nelson (1965) that mentioned hypertext for the first time focused on the user as producer of knowledge and the implications of transformation of knowledge as is reflected in its title A File Structure for the Complex, the Changing and the Indeterminate. However, whereas Licklider in his conceptualizations of topical space explored the logic and semantics of language, Nelson merely focuses on the visibility of what he calls, in Dream Machines (1974), collateral structures and the display hereof for the user of computers. The principle of collateration, that is, the creation of multiple and viewable links between any two data structures, is simple. However, the handling of links for rapid and convenient viewing in processes of text writing, editing, annotating, etc. is rather complex.

To solve that problem, Nelson started with the Parallel TextFace and Xanadu projects in 1972 and that finally merged in the development of Xanadu Space software on which he is still working today. Nelson describes that, in the early days of developing his ideas of hypertext when he was working on a socalled "parallel vision editor" in 1972, the computer still had very limited visualization possibilities (Nelson, 1987, 41-42). For that reason, he glued paper arrows on celluloid film attached to a piece of card board to simulate cross-linking on a computer screen. Only later, when the computer allowed for simulations in a more dimensional space, was Nelson able to work out and visualize his ideas in Xanadu Space.

In the meantime, Tim Berners-Lee had developed the World Wide Web as a publication application on top of the Internet. Berners-Lee considered hypertext as one of the building stones of the World Wide Web in addition to the Internet (Berners-Lee 2000). Nelson probably shared Berners-Lee's initial dream of the future of the WWW as an environment in which people (Web 2.0) and computers (Semantic Web) collaborate in producing knowledge clashes with his views on its further development from an information-architectural point of view. In polemic state- ments, Nelson fights against the implicit hierarchies in the further development of the World Wide Web that, in his view, is still an imitation of paper (Nelson 2004, Nelson and Adamson Smith, 2007). Nelson and Adamson Smith (2007) write:

Much of the field has imitated paper: in word processing (Microsoft Word and Adobe Acrobat) and the World Wide Web, whose rectangular page layouts become a focal issue. It should be noted that these systems imitate paper under glass.

The project XanaduSpace aims at linking information in a non hierarchical way and, at the same time, to tackle the problem of the readability of this information that is projected in various dimensions (Nelson and Adamson Smith 2007):

We are not just building a different kind of hypertext, but seeking the most general form of document. The issue is bow to represent all possible documents. ... Our document structure is very different from paper (although rectangularity is allowed as an option). A document may be divided into arbitrary units; the default visualization is a vertical strip, but very different structures and presentations are also possible. A document may consist of any number of such pieces, which we call "vunits," or viewable units." ... These are intended not just as novelties, but as full-status content packages: all contents are linkable [and] transclusible (showing their origins). They may all be connected sideby-side, like columns in a book, table or spreadsheet.

It is, indeed, a very promising project to tackle the problem of reduction that we discussed in mappings of a multi-dimensional universe of knowledge along a one-dimensional space (line). Instead of reducing dimensions as a compromise to fit the classification and synthesis or, to recall Ranganathan's words, "to chose forcedly one," the units in Xanadu space are viewable at will in a continuum of one and multidimensional space. In order not to get "lost in cyberspace," the project included "a system of side by side viewing." It entails the development of a new viewing mechanism called "the reading plane, or line of fire" (Figure 6b). This reading plane shows a current page or vunit in 3space, at center screen. It allows for close-up reading in a larger context-showing both content and con- 


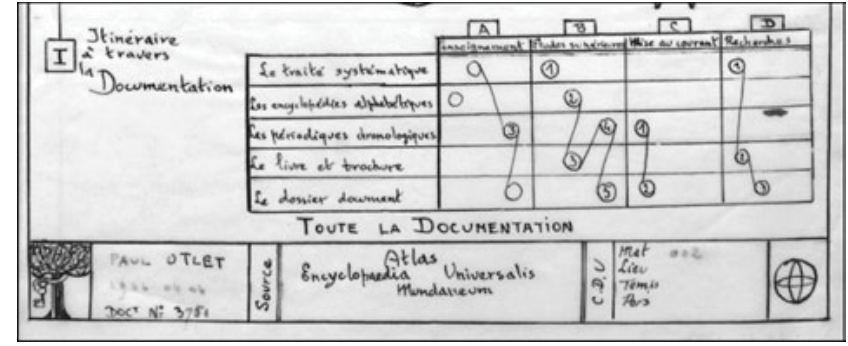

Figure 6a. Otlet Itineary through Documentation (C) Mons, Mundaneum EUM 3751 - 6 April 1944)

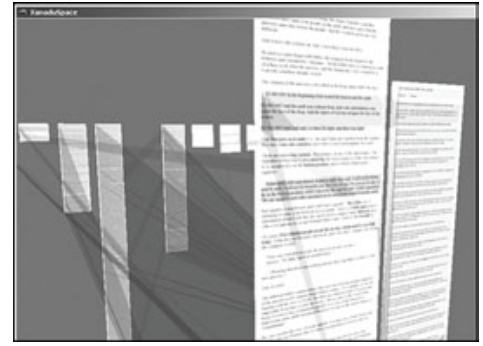

Figure 6b. Nelson and Adamson (2007) Parallel vision of documents linked by 'lines of fire' in Xanadu Space (C)

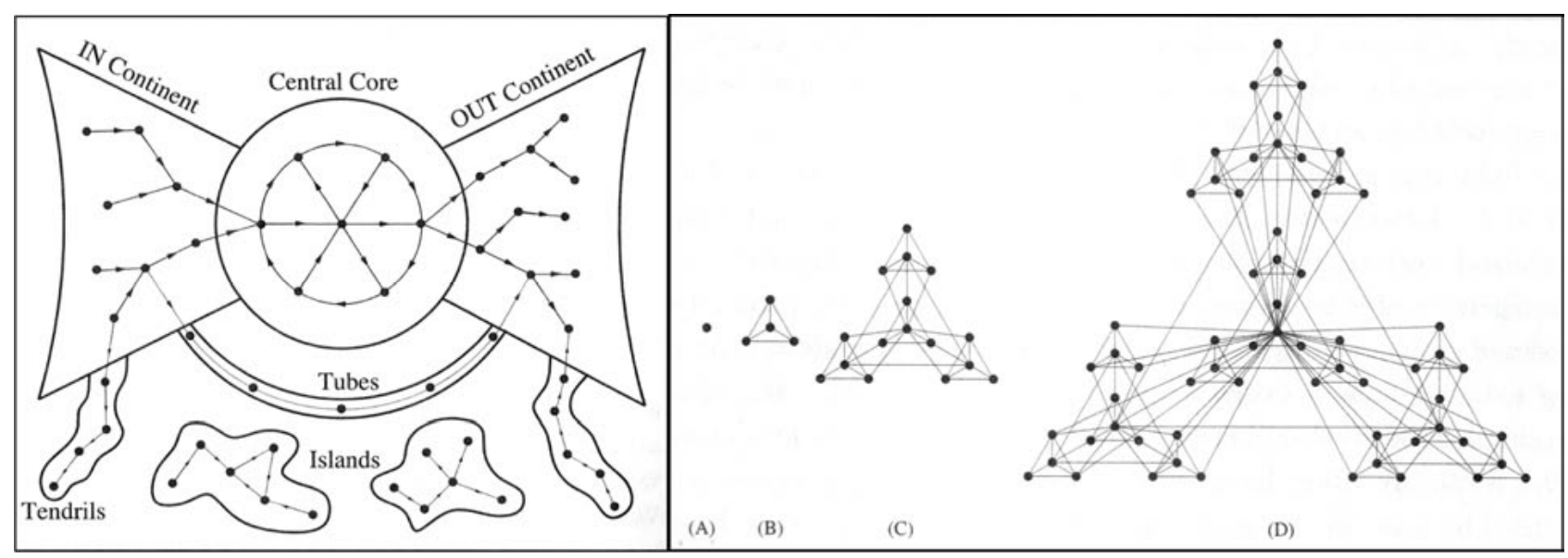

Figure 7. Barabási (2003): Fragmented Web: directional web with “continents” and hierarchical modular growth. London: Plume-Penguin group. (c)

nections to vunits elsewhere. The makers also suggest the extension into a fourth dimension showing its physical changes and value over time and other dimensions showing parametric variations (Nelson and Adamson Smith 2007).

The "system of side by side viewing" consists of temporary view of minimal two data structures that make part of the total dynamic storage of the Xanadu systems in which new units (Nelson also calls them documents) are built out of material in old units. This temporary views can be seen, as events in Nelson dynamic network of "interconnected ideas." Nelson envisions that the Xanadu network work will be built up rapidly by users. In his 1974 Dream Machines, Nelson $(1987,144)$ wrote: "In the year 2020, we imagine a network with a least a hundred million simultaneous users, adding a hundred million documents an hour to the system."

We do not know whether Nelson's vision of million users using Xanadu Space in 2020 will have become true, if ever. But what we do know is that the World Wide Web will be evolved by then in a much different way than that he envisioned, with huge consequences for information retrieval.

\subsection{Conclusion: The future of information retrieval}

We observed that Licklider stated in 1965 that complete integration of knowledge was not in reach and that, for the time being, only diverse partial models of the universe could be used. We also noted that librarians gradually made place for users as organizers of knowledge. However, even in the case that Nelson's dream of million users will come true, they will shape the future development of the World Wide Web, but not necessarily be able to influence it to great extent. Albert-Lászó Barabási (2003) describes in Linked that the Web's architecture is the product of two important layers: code and collective human actions taking advantage of code. However, he adds that the science of the Web increasingly proves that this architecture represents a higher level of organization than code (Barabási 2003, 175). His mappings of the World Wide Web at different intervals give some indication about 
its future structure. Barabási describes the World Wide Web as a directed network that naturally will break down into continents, resulting in what he calls: "The Fragmented Web” (Barabási 165-172) (Figure 7). This web of fragmented clusters is formed by a combination of processes of hierarchical modular growth and scale free self-organization (Barabási 2003, 232-237). In this predictive model, the web will be built up from highly hierarchical clusters which are very popular by the search engines and a large quantity of nodes with only a few small incoming links and that will be ignored by their robots (Barabási 2003, 58).

So, apart from the prediction that the future of the World Wide Web will be more conditioned by its topological structure than by code, it will also consist of large invisible parts (Barabási 2003, 175). This combination of dependency on topological structure of the World Wide Web and the limitations in the visibility of its structure and development requires new approaches in information retrieval. The dream of data integration seems even more remote than in 1965 when Licklider observed that a choice for separate models of the universe was inevitable. If we read $\mathrm{Ba}$ rabási's predictive mappings correctly there will be an increase of various constellations of sub-universes or even of multiple universes (a multiverse) similar to the descriptions of the real outer space by some astro-physicists. Constellations with well-ordered parts of knowledge and vague fields of floating isolates. Barabási projected the multidimensional space of the World Wide Web on a two-dimensional one, comparable to Mercator's projection of the globe on a rectangular grid map in the 16th century. Due the limitations of the paper format of the book, the multidimensional space of the World Wide Web is reduced to a diagrammatic Flatland. In that sense, Barabasi's map of the web is not different from the representations of Otlet and Ranganathan in which they reduced multidimensional organization of knowledge in facets to a line (compare figures $1 \mathrm{a}$ and $\mathrm{b}$ ). Moreover, Barábasi visualized some in- and outflows (based on western reading conventions, from left to right) that give direction to development of the web. However, his map does not provide insight in the dynamics of the multidimensional knowledge and the forces (code, clicking behavior, etc.) that shape his "continents and islands" of information in the World Wide Web. The limitations of that geographical metaphor of knowledge production is expressed well by the Romanian astro-physicist Basarab Nicolescu (2006, par. 1b), who, in a different context, that of boundaries between disciplines, argued:
For them [those who cannot think in terms of discontinuity red.], the boundaries between disciplines are like boundaries between countries, continents and oceans on the surface of the Earth. These boundaries are fluctuating in time but a fact remains unchanged: the continuity between territories. We have a different approach of the boundaries between disciplines. For us, they are like the separation between galaxies, solar systems, stars and planets. It is the movement itself which generates the fluctuation of boundaries. This does not mean that a galaxy intersects another galaxy. When we cross the boundaries we meet the interplanetary and intergalactic vacuum. This vacuum is far from being empty: it is full of invisible matter and energy. It introduces a clear discontinuity between territories of galaxies, solar systems, stars and planets. Without the interplanetary and intergalactic vacuum there is no Universe.

Basarab Nicolescu used the universe of knowledge metaphor to explain his theory of transdisciplinarity. This theory is based on a pragmatic, but at the same time, ontological view that "reality" consists of a multitude of levels. It allows Nicolescu to tackle the problem of reduction of multidimensional knowledge and to provide an explanation for the dynamics- that is, for the interactions-within the (knowledge) universe. Whereas the clear separation between object and subject in the knowledge organization models of Otlet and Ranganathan corresponds with the conceptions of space and time and the laws of causes and effect in classical physics, Nicolescu bases his theory of transdisciplinarity on quantum physics. Nicolescu (2009) provides a model-which in the context of this article can only be touched upon briefly-in which reality is not just considered as one object that is separate of the subject, but in which levels of reality of the object and levels of reality of the subject (each level with its own space-time) are in continuous interaction with each other. The interaction between these layers plays against the background of the "hidden third" in which they are immersed. So-called middle-logic allows us to jump from one level of reality to another. In a "zone of non-resistance," two contradictory elements or perceptions can meet on a different level of reality. This is explained in Figure 8 in which $\mathrm{A}$ and non-A appear to be contradictory on one level of reality (NR 2), but appear to be united at a particular moment on another level of reality (NR 1), the so-called T- state of the included middle. 


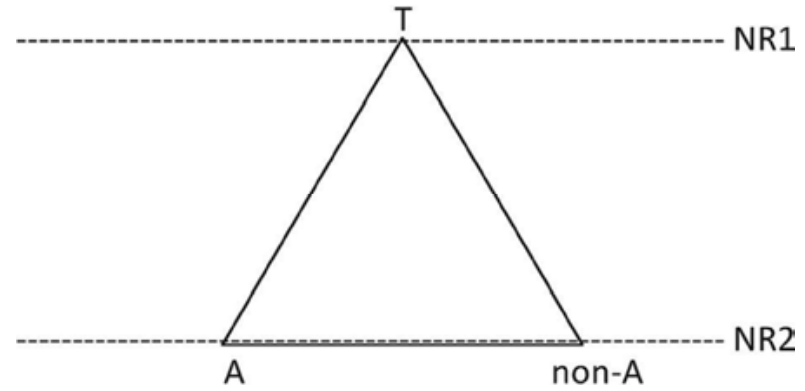

Figure 8. After Nicolescu: Transdisciplinarity:

The Hidden Third between the Subject and the Object

(Fig 2: Symbolic representation of the action of the included middle logic) Contradiction between a and non-a on level of reality NR 2 united in T state on level of reality NR 1

Nicolescu $(2009,5)$ underpins his model with rather unknown philosophical writings of the famous physicist Werner Heisenberg (which he recognized later), who described reality as a continuous fluctuation of experience. For that reason, reality in the view of $\mathrm{Ni}$ colescu cannot be reduced to substance, but is identifiable in the "complexus substance-energy-space-timeinformation." Furthermore, he quotes the logician Charles Sanders Peirce (15), who questioned the existence of reality, but who argued that, if there is a reality, it has to consist in the fact that "the world lives, moves and has in itself a logic of events, which corresponds to our reason."

From the perspective of these theories that describe reality as visible and unvisible, as being in continuous flux and as not reducible to substance, we might consider a model for information retrieval not aimed at complete data-integration, but that takes the interaction in a multidimensional knowledge space, or rather spaces, as point of departure. This model should allow for the creation of temporary interfaces between the hierarchical ordered parts, such as classifications and more fluid ones, such as folksonomies. Temporary, because, in the above explored multiverse of knowledge, with many black holes and structures with different dynamics, it will be hard to give knowledge particles a place. At best, we can provide snapshots of the elements we see-Nelson's 'vunits'-in relation to what is visible of the web in continuous flux to which it belongs. For that reason, it might be useful to explore XanaduSpace further. Not with Nelson's intention to re-order or replace the World Wide Web with it-we must accept the reality that the Web has evolved in a certain irreversible way-but for its qualities of parallel vision. It provides the possibility, explored by many classificationists such as Otlet and Ranganathan to map of multi-dimensional knowledge spaces on a line, without the compromises they had to make to give an elements a place. And it might even provide "transdisciplinary visions on multiple levels" as desired by Nicolescu and others, when multiple perspectives can be lined out up in parallel vision at the same time. Moreover, the outcomes of experiments of creating temporary interfaces with parallel vision, the temporary views of knowledge parts in relation to the visible, could be described with models known within philosophy (compare Pierce, Whitehead, Heisenberg) and knowledge interaction (Smiraglia and Van den Heuvel 2011). Moreover, the temporary interfaces might be compared with the events in the work of Whitehead and Russell or the $\mathrm{T}$ states in the Nicolescu model and assessed whether they can be described in terms of event-ontologies (Shaw 2010) or instantiation (Smiraglia 2008). We are in need of new conceptualizations of multidimensional classification not based on data-integration, but on the visualization of temporary interfaces to knowledge interaction.

\section{References}

Barabási, Albert-László. 2003. Linked: how everything is connected to everything else and what it means for business, science, and everyday life, London: PlumePenguin group.

Beghtol, Clare. 2008. From the universe of knowledge to the universe of concepts: The structural revolution in classification for information retrieval. Axiomathes 18n2: 131-44.

Berners-Lee, Tim. 1998. Design issues 'What the semantic web can represent,' paragraph: 'Knowledge Representation goes global” [last modified 17 Sept. 1998]. Available http://www.w3.org/DesignIssues/ RDFnot.html

Berners-Lee, Tim. 2000. Weaving the Web: the original design and ultimate destiny of the World Wide Web. New York: Harper-Collins.

Bliss, Henry Evelyn. 1929. The organization of knowledge and the system of the sciences. New York: $\mathrm{H}$. Holt and Co.

Cordonnier, Gérard. 1944. Classification et classement. Extrait du bulletin d'information scientifique et technique 6.

Donker Duyvis, Frits 1951. The UDC: what it is and what it is not, Reviere of documentation 18n2: 99105.

Farradane, Jason E.L. 1952. A scientific theory of classification and indexing: further considerations. The journal of documentation 8n: 73-92. 
La Barre, Kathryn. 2006. The use of faceted analyticosynthetic theory in the practice of website construction and design, Ph.D. dissertation. Bloomington: Indiana University School of Library and Information Science. Available https://netfiles.uiuc.edu/ klabarre $/$ www $/$ LaBarre_FAST.pdf? uniq $=2$ gi38c

Licklider, J. C. R. 1965. Council on Library Resources., and Bolt, Beranek, and Newman, Inc. Libraries of the future. Cambridge, Mass.: The M.I.T. Press.

Miksa, Francis L. 1992. The concept of the universe of knowledge and the purpose of lis classification. In: Williamson, N.J. and Hudon, M. eds., Classification research for knowledge representation and organization: Proceedings of the 5th International Study Conference on Classification Research Toronto. Amsterdam: Elsevier, pp. 161-78.

Miksa, Francis L. 1998. The DDC, the universe of knowledge, and the post-modern library. Albany, N.Y.: Forest Press.

Nelson, Theodor H. 1965. A file structure for the complex, the changing and the indeterminate. In Berendt, Bettina et al. eds., Proceedings of the ACM $20^{\text {th }}$ National Conference. New York: ACM, pp. 84100.

Nelson, Theodor. H. 1987. Computer lib/dream machines, introduction by Stewart Brad. Rev. ed. Redmond, Wash.: Tempus Books of Microsoft Press.

Nelson, Theodor H. 2003. 'I don't buy in', Available http://ted.hyperland.com/buyin.txt.

Nelson, Theodor H. 2004. A cosmology for a different computer universe: data model, mechanisms, virtual machine and visualization infrastructure, Journal of digital information 5 no. 1. Available http://journals.tdl.org/jodi/article/view/131.

Nelson, Theodor H. and Adamson Smith, Robert. 2007. Back to the future: bypertext the way it used to be. Available http://xanadu.com/XanaduSpace/ btf.htm.

Nicolescu Basarab. 2006. Transdisciplinarity: past, present and future. In: Haverkort, Bertus and Reijntjes, Coen, eds. Moving worldviews, reshaping sciences : policies and practices for endogenous sustainable development, Compas series on world views and sciences 4. Leusden : COMPAS, pp. 142-166. Available http://basarab.nicolescu.perso. sfr.fr/Basarab/Docs_articles/Worldviews2006.htm

Nicolescu, Basarab. 2009. Transdisciplinarity : the hidden third, between the subject and the object. Invited talk at the International Workshop Science, spirituality, society, Cluj-Napoca, Romania, 21 May 2009. Available http://basarab.nicolescu.perso.sfr. fr/Basarab/Docs_articles/ClujHiddenThird052009 Proceedings.pdf.

Otlet, Paul.1907. l' Organisation systématique de la documentation et le dévéloppement de l'Institut Internationale de la Bibliographie, IIB Bulletin 12: 3-64.

Otlet, Paul. 1908. Theorie schematique de la Classification. Manuscript: Mons Mundaneum PPPO 0956EUM Farde 9 N. 39.

Otlet, Paul. 1928. Relations fondamentales. Manuscript: Mons Mundaneum PPPO 0956- EUM Farde 9 N. 63.

Otlet, Paul. 1935. Monde, essai d'universalisme: connaissance du monde, action organisée et plan du monde. Bruxelles: Editiones Mundaneum/D.van Keerberghen \& Fils.

Ranganathan, Shiyali R. 1951, Colon classification and its approach to documentation. In Shera, Jesse H. and Egan Margaret E. eds., Bibliographic organization: Papers presented before the Fifteenth Annual Conference of the Graduate Library School July 24-29, 1950,. Chicago: The University of Chicago Press, pp. 94-105.

Ranganathan, Shiyali R. 1957. Prologomena to library classification. $2^{\text {nd }}$ ed. London: The Library Association.

Ranganathan, Shiyali R. 1961. Sayers and Donker Duyvis. Theory and maintenance of library classification. Annals of library science, 8: 85-99.

Ranganathan, Shiyali R. 1967. Prolegomena to library classification. $3^{\text {rd }}$ ed. London: The Library Association.

Rayward, W. Boyd. 1975. The universe of information: The work of Paul Otlet for documentation and international organisation. Moscow: Published for International Federation for Documentation (FID) by All-Union Institute for Scientific and Technical Information (VINITI).

Rayward, W. Boyd. 1994. Visions of Xanadu: Paul Otlet (1868-1944) and hypertext. Journal of the American Society for Information Science 45: 23550.

Shaw, Ryan. 2010. Events and periods as concepts for organizing historical knowledge. Ph.D. dissertation. University of California, Berkeley. Available http:// aesh.in/diss.

Shera, Jesse H. 1951. Classification as the basis of bibliographic organization. In Shera, Jesse H. and Egan, Margaret E. eds., Bibliographic organization: Papers presented before the Fifteenth Annual Confer- 
ence of the Graduate Library School July 24-29, 1950, Chicago: The University of Chicago Press, pp. 72-93.

Shera, Jesse H. 1957. Pattern, structure, and conceptualization in classification. In Shera, Jesse H. and Egan, Margaret E. eds., Proceedings of the International Study Conference on Classification for Information Retrieval beld at Beatrice Webb House, Dorking, England 13-th-17thMay 1957, ASLIB 4 London/New York: Pergamon Press, pp. 15-27.

Smiraglia, Richard.P. 2008. A meta-analysis of instantiation as a phenomenon of information objects. Culture del Testo e del Documento 9 no. 25: 5-25.

Smiraglia Richard P. and Van den Heuvel, Charles. 2011. Idea Collider: from a theory of knowledge organization to a theory of knowledge interaction. Bulletin of the American Society of Information Science and Technology 37n4: 43-7.

Smiraglia, Richard P., Van den Heuvel, Charles and Dousa, Thomas M. 2011. Interactions between elementary structures in universes of knowledge. In: Slavic, Aïda and Civallero, Edgardo eds., Classification \& Ontology: Formal Approaches and Access to Knowledge: Proceedings of the International UDC Seminar, 19-20 September 2011, The Hague, Netherlands. Würzburg: Ergon Verlag, pp. 25-40.

Spencer, Herbert. 1864. The classification of the sciences: which are added reasons for dissenting from the philosophy of M. Comte. New York: D. Appleton and Co.

Van den Heuvel, Charles. 2008. Building Society, constructing knowledge, weaving the web: Otlet's visualizations of a global information society and his concept of a universal civilization. In Rayward, W. Boyd ed., European Modernism and the Information Society. Aldershot: Ashgate, pp. 127-53.

Van den Heuvel, Charles and Smiraglia, R.P. 2010. Concepts as particles: metaphors for the universe of knowledge. In Gnoli, Claudio and Mazzocchi,
Fulvio eds., Paradigms and conceptual systems in knowledge organization: Proceedings of the Eleventh International ISKO Conference, 23-26 February 2010 Rome Italy, Würzburg: Ergon-Verlag, pp. 5056.

Van den Heuvel, Charles and Akdag Salah, Almila. 2011: Visualizing universes of knowledge. In Slavic, Aïda and Civallero, Edgardo eds., Classification \& Ontology: Formal Approaches and Access to Knowledge: Proceedings of the International UDC Seminar, 19-20 September 2011, The Hague, Netherlands. Würzburg: Ergon Verlag, pp. 283-94.

Van den Heuvel, Charles and Rayward, W. Boyd. 2011. Facing interfaces: Paul Otlet's visualizations of data integration, Journal of the American Society for Information Science and Technology 62: 2313-26.

Van den Heuvel, Charles. 2012 forthcoming. The Dutch Connection. Donker Duyvis and perceptions of American and European decimal classification systems in the first half of the 20th Century. In Proceedings of ASIST 75th Anniversary History Pre-Conference, Baltimore 27 October 2012.

Van den Heuvel, Charles 2013 forthcoming. Dynamics in networks and in decimal classification systems in the first half of the 20th Century. In Rayward, W. Boyd ed., Transcending boundaries in Europe in the period of the Belle Epoque: organizing knowledge, mobilizing networks, and effecting social change. Aldershot: Ashgate.

Whitehead, Alfred North.1945. Science and the modern world. Cambridge: Cambridge University Press.

Whitehead, Alfred North. 1967. Adventures of ideas. New York: Free Press

Wikipedia. 2011. Projective geometry http://en.wiki pedia.org/wiki/Projective_geometry

Wilson Thomas Daniel. 1972. The work of the British Classification Research Group. In: Wellisch, Hans and Wilson, T.D. eds., Subject retrieval in the seventies: new directions. Westport, CO: Greenwood Publishing, pp. 62-71. 